\title{
Evaluation of the resistance of trussed slabs with steel formwork in cold formed U profile
}

\author{
Lucas Fadini Favarato ${ }^{a^{*}}$ \\ Adenilcia Fernanda G. Calenzani ${ }^{a}$ \\ Juliana C. Vianna Pires ${ }^{\mathrm{a}}$ (D) \\ Elisabeth Junges ${ }^{\mathrm{a}}$ (iD \\ Johann A. Ferrareto ${ }^{b}$

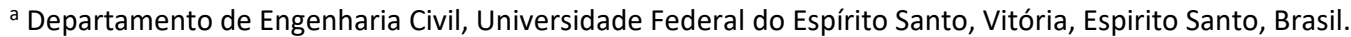 \\ E-mail: lucasffavarato@gmail.com, afcalenzani@gmail.com, jcvianna30@gmail.com, bethjunges@gmail.com \\ ${ }^{\mathrm{b}}$ ArcelorMittal, Serra, Espirito Santo, Brasil. E-mail: johann.ferrareto@arcelormittal.com.br \\ *Corresponding author
}

http://dx.doi.org/10.1590/1679-78255304

\begin{abstract}
In the last decades, the modernization in structural engineering has increased the use of steel-concrete composite and hybrid systems for slabs, when the adherence in the interface of the materials is present or not, respectively. In addition to the traditional steel deck, a similar solution for precast trussed slabs has been used for small constructions, in which a cold formed $U$ profile acts as steel formwork before the concrete curing, resisting to self-weight of the concrete and to the construction overload. After this period, the steel profile gets incorporated to the concrete element, allowing the composite behavior of the structure, system that usually goes without additional reinforcements. This slab includes, besides concrete, a light filling material between ribs, cold formed profiles and the trussed reinforcement. Once this technology has just arrived to the construction market, there is a gap of knowledge related to its design procedure. In this context, this study aims to present a methodology to analyze the limit-states that govern the design of these slabs. A computational tool was developed to evaluate the resistance through data entry related to geometry, service loads and materials, which grants to conduct a parametric study with pre-defined geometries to obtain, as result, spans and loads. Conclusions about the maximum span without shoring and general data are also discussed.
\end{abstract}

\section{Keywords}

Steel-concrete composite slabs, trussed slabs, cold formed U profile, design procedure.

\section{INTRODUCTION}

Since the beginning of XX century, the design solutions based on steel and steel-concrete composite structures have gained technical and economic competitiveness when compared to common design solutions, as pure reinforced concrete. According to Carvalho et al. (2014), this is owed to several factors, as steel lightness, simple and quick structural assembly and to the quality of the final product.

In the range of steel structures, many projects are now taking advantages of the cold formed steel (CFS) profiles, obtained from thin plates folding and with high mass/resistance rate. These elements are made from plates which thicknesses vary between 0.4 and $8.0 \mathrm{~mm}$, according to National Brazilian Code ABNT NBR 14762 (2010). Javaroni 
(2015) also states that the major advantage in the use of this structural technology is related to the fabrication process: thin plates, with small resistance in its original shape, are stiffened where buckling can occur. Hence, the folding procedure changes steel original mechanical properties, leading to highest yield and ultimate strengths. Otherwise, residual stresses may come up, reducing the ductility of the material.

Whereas rolled and welded steel profiles are more suitable for medium and large constructions, cold-formed ones are commonly used in small and medium constructions to compose roof structures, composite slabs and beams, mezzanines, popular houses, small warehouses and up-to-four-storey buildings. In addition, many cross sections are available for design, as C, Z, L and hat, doubled or not, stiffened or not (Silva et al., 2014).

One important application of cold formed steel profiles in structural engineering, as presented previously, is in composite slabs. It gets incorporated to concrete after curing, allowing the composite behavior, and works as reinforcement, usually sparing additional ones. Besides, it's necessary to verify the structural safety before concrete curing, in which the steel formwork acts as a single steel beam and must resist to all ultimate limit states that can occur in construction stage. It's also important to state that in the composite phase the ultimate limit state which governs the design is the longitudinal shear in the interface of the materials, causing slipping in that region.

In the literature there are numerous articles that present design procedures for composite slabs, including numerical and experimental analyses. Takey (2001) has evaluated the resistance of composite slabs with ribs filled with light material, the same of that used in precast concrete slabs. In a first moment, the optimum geometry of the profile has been determined for three different thicknesses (1.52, 2.00 and $3.00 \mathrm{~mm}$ ) and then full-scale tests were conducted to assess the ultimate limits and the longitudinal shear resistance as well. The results were satisfactory and the research concluded that this system for slabs is competitive. Vianna (2005) proposed a new geometry for the cold formed steel section, using other different plate thicknesses $(0.80,1.00$ and $1.20 \mathrm{~mm})$. Full-scale tests were also conducted to determine ultimate load, deflections, stiffness during concreting and modes of failure. The results were also satisfactory when compared to theoretical results. Sieg (2015) suggested the use of a trapezoidal formwork, the profile MD55, with two different thicknesses $(0.80$ and $1.20 \mathrm{~mm}$ ). The experimental program was preceded by the analysis of the profile, resisting to its self-weight and overloads before concrete curing. Then, fourteen prototypes of composite slabs have been tested to evaluate the ultimate resistance. As a result, the $m-k$ design equation has been estimated based on the ultimate limit state of longitudinal shear. Grossi (2016) evaluated the influence of additional reinforcements in composite slabs against the increase of plate thickness to reach big spans. A mathematical formulation for design has been suggested to contemplate additional reinforcements and, then, full-scale tests were conducted, confirming the efficiency of this system and validating the proposed methodology.

Furthermore, there are also numerous papers in the literature where numerical procedures for buckling analysis in CFS elements are detailed as well as pertinent recommendations for linear instability or buckling problems are made. Kankanamge and Mahendran (2012) proposed a finite element numerical study to investigate the lateral-torsional buckling behavior of CFS stiffened channel sections simply supported beams uniformly bent about the axis of major inertia. The numerical results were calibrated with available numerical and experimental data. After comparing the moment capacity to normative prescriptions, Eurocode 3 Part 1.3 (2006) was considered conservative while AS/NZS 4600:2005 was not considered conservative. Then, the authors proposed modifications in the design codes. Ibrahimbegovic et al. (2013) used the von Karman strain measure to propose an original procedure to evaluate critical buckling loads of elements that experience extreme mechanical or thermomechanical conditions, providing a special format to the tangent stiffness matrix. The procedure efficiency was confirmed after performing the validation examples, in special when compared to a computational alternative base upon finite strain elasticity as well as a model using frame elements. Cheng et al. (2013) assessed the influence of combined bending and compression in the buckling modes of CFS lipped channel sections bent about both main axes. He stated that a non-symmetric pre-buckling stress distribution appears when the element is bent about the minor inertia axis, the critical compression load is reduced when the lips undergo a compressive stress. Ngo et al. (2014) developed a thermo-mechanical model, its discrete approximations and a solution algorithm to deal with nonlinear instability problems of combined material instability due to softening and geometric instability at large displacements. Simulations were presented to prove the high performance of the method. Finally, Glauz (2017) investigated the buckling behavior of CFS point-symmetric and nonsymmetric sections as well as sections oriented to non-principal axes, developing a general formulation to predict the critical bending moments of beams under lateral-torsional buckling, equation that actually covers all CFS cross sections.

In the past five years, a similar product was developed by ArcelorMittal for composite ribbed slabs uniting a stiffened $C$ cold formed profile, light filling material between ribs, additional reinforcements and concrete. Although, a steel truss is added to the set in order to increase the resistant capacity. In this context, this work seeks to present a design procedure for these slabs with no shoring whilst no full-scale tests results are available and there's no 
information about slipping resistance in the steel-concrete interface. Before concrete curing, the steel formwork in cold formed profile resists to all loads of construction and self-weight. Then, once no interaction is still provided, only the concrete resists to ultimate overloads. The design procedure was based on National Brazilian Codes ABNT NBR 14762 (ASSOCIAÇÃO BRASILEIRA DE NORMAS TÉCNICAS, 2008, 2009, 2010, 2014, 2016), ABNT NBR 8800 (2008), ABNT NBR 6118 (2014) and ABNT NBR 14859-2 (2016).

\section{PROPOSED DESIGN PROCEDURE}

Consider, in the first moment, the geometry and structure of this slab, as indicated in Figure 1. It's composed by the cold formed $U$ profile, bent about the minor inertia axis, the steel truss coupled to the steel formwork, additional reinforcements when necessary, light filling material and a concrete layer.

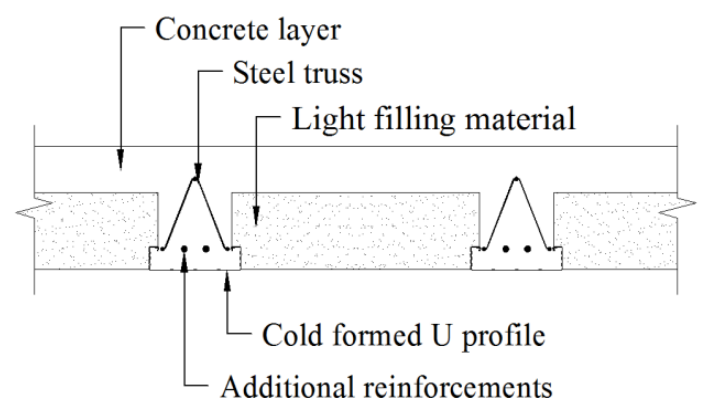

Figure 1: Cross section of trussed slab with steel formwork in cold formed U profile.

The size of the cold formed profile cross section is predefined, as indicated in Figure 2. There are also three stiffeners in each flange and three in the web, with edge and additional stiffeners as well. The thickness is indicated as $t_{s}$ and assumes the values of $0.65,0.80$ and $1.08 \mathrm{~mm}$.

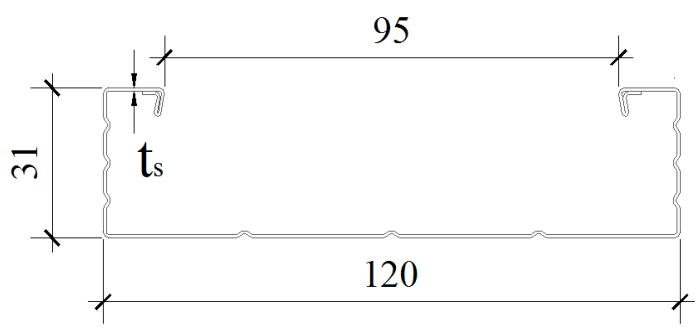

Figure 2: Cross section of cold formed $U$ profile $(\mathrm{mm})$.

The dimensions of the concrete $T$ cross section, in $\mathrm{cm}$, are related to the geometry of the light filling material ( $b_{b}$ indicates the width and $h_{b}$ the height of the blocks), steel section and concrete layer height $\left(h_{c}\right)$, according to Equation 1 and Figure 3.

$b_{f}=b_{b}+9.5$

$h=h_{b}+h_{c}$

$h_{f}=h_{c}$

$b_{w 1}=9.5$

$b_{w 2}=12.0$

$h_{w 1}=h_{b}-3.1$

$h_{w 2}=3.1$ 


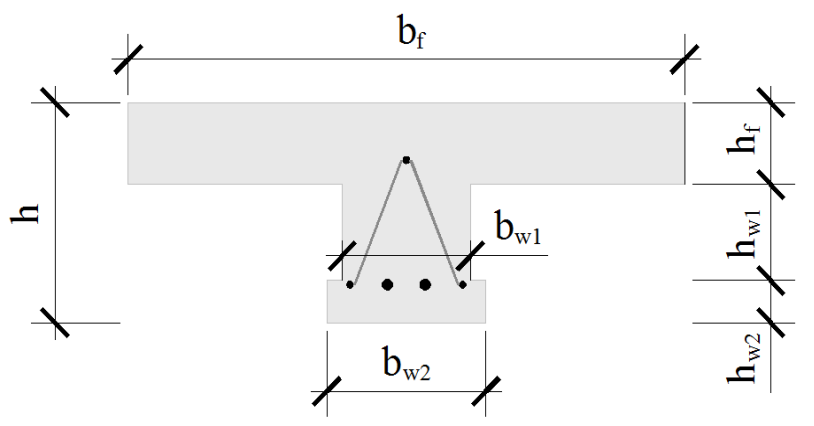

Figure 3: Concrete T cross section.

The design of these slabs considering ultimate and serviceability limit states involves two steps. First of all, it's necessary to analyze the concrete after curing resisting to bending and shear, and also controlling the maximum total deflection, which includes the effects of creep and shrinkage, and maximum crack width. For a given span, $L$, it's possible to calculate the overload, in $\mathrm{kg} / \mathrm{m}^{2}$, that leads to the first limit state considering the appropriate load combination for each one.

Then, with the previous result of span, the steel formwork should be verified for the limit states before concrete curing, which are instabilities caused by bending moment, web buckling caused by shear force and excessive deflection. It's important to state that no interaction is provided, once there's no data available from full-scale tests, reason why it's called hybrid system. Besides, each rib is analyzed as a single beam.

In the sequence, all the input needed data are listed: dimensions and specific weight of light filling material; concrete layer thickness; concrete compressive strength; model of chosen steel truss; size, quantity and yield strength of reinforcements when needed; yield strength of steel used in the truss; environmental aggressiveness class according to ABNT NBR 6118 (2014); maximum deflection allowed before concrete curing according to ABNT NBR 6118 (2014); maximum deflection allowed after concrete curing according to ABNT NBR 8800 (2008); and span.

\subsection{Design after concrete curing}

The design of concrete beams to bending moment and shear force may guarantee the structural safety by preventing concrete collapse and excessive deformation of reinforcements. In this sense, standard proceedings proposed a methodology based on some assumptions, as the Bernoulli's Hypothesis and the replacement of a nonlinear stress distribution by a constant one, whose amplitude is $\lambda x$, in which $x$ represents the depth of the neutral axis, measured from the top of the cross section, and $\lambda=0.8$ when $f_{c k} \leq 50 \mathrm{MPa}$, and whose value is $85 \%$ of design compressive strength $\left(f_{c d}\right)$.

In general terms, the design should be done in the $3^{\text {rd }}$ domain of deformations, where the relative depth of neutral axis, $x / d$ ( $d$ is the distance from the center of gravity of tensioned reinforcements set to the top of the section), may varies between 0.259 and 0.628 . Although, in order to guarantee the ductile behavior, the neutral axis depth is restrained to $0.45 d$ when $f_{c k} \leq 50 \mathrm{MPa}$.

\subsubsection{Resistance to bending moment}

Figure 4 shows the distribution of forces due to bending moment. The reduced neutral axis depth, $\lambda x$, may be in the flange or web of $\mathrm{T}$ section. In this sense, before calculating the resistant moment, it shall be settled by equilibrium of horizontal forces $C$, acting in the upper truss reinforcement, $T$, acting on lower truss reinforcements and additional ones, and $R=\eta f_{c d}$, the compressive resultant on concrete. It's important to state that $C$ can be either a compressive or tensile force depending on the geometry of the section, truss height and concrete compressive design strength $\left(f_{c d}\right)$. 


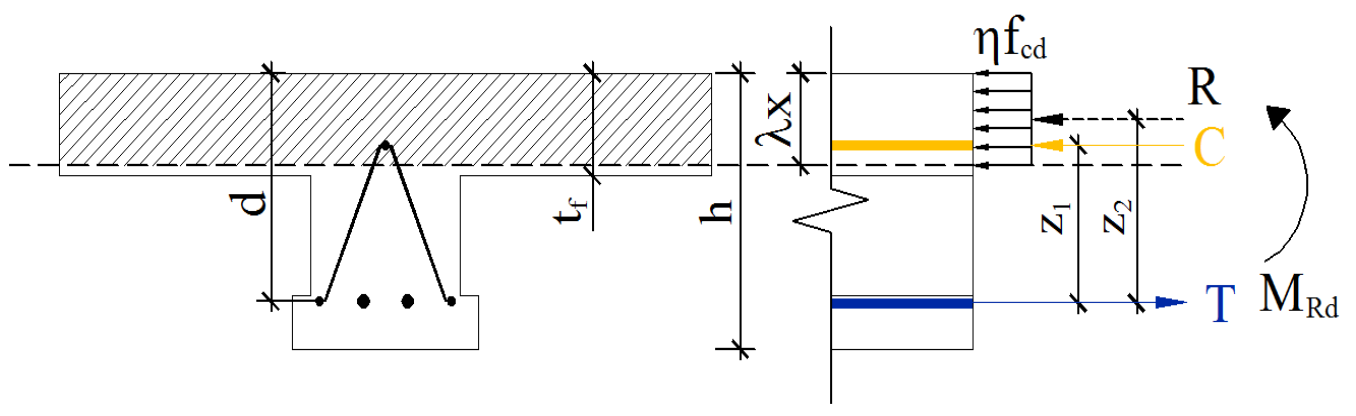

Figure 4: Distribution of stresses and forces in the concrete T cross section.

Considering the neutral axis crosses the flange, the equilibrium is expressed as follows:

$-\eta f_{c d} b_{f} \lambda x+E_{s} \varepsilon_{s t} A_{s, c t}+f_{y d}\left(A_{s, t t}+A_{s, t a}\right)=0$

$\lambda x \leq t_{f}$

where $b_{f}$ is the flange width, $E_{s}$ is the steel Young's Module, $\varepsilon_{s t}$ is specific deformation (also depends on $x$ ) and $A_{s, c t}$ is the area of the upper truss reinforcement, $f_{y d}$ is yield strength of steel, $A_{s, t t}$ is the area of lower truss reinforcement and $A_{s, t a}$ is the area of additional ones. If the value obtained with Equation 2 does not satisfy Equation 3, then the neutral axis crosses the web and its depth may be calculated using Equation 4.

$-\eta f_{c d}\left(b_{f}-b_{w 1}\right) h_{f}-\eta f_{c d} b_{w 1} \lambda x+E_{s} \varepsilon_{s t} A_{s, c t}+f_{y d}\left(A_{s, t t}+A_{s, t a}\right)=0$

$\lambda x>t_{f}$

where $b_{w 1}$ is the web thickness, according to Figure 3 , and $h_{f}$ is the flange thickness. The value now may satisfy Equation 5. Once the force distribution is now known, the distances $z_{1}$ and $z_{2}$ from the action lines of $T$ to those of $C$ and $R$, respectively, the resistant bending moment in the concrete section, $M_{R d, c}$, is easily accounted by:

$M_{R d, c}=C z_{1}+R z_{2}$

\subsubsection{Resistance to shear force}

Araújo (2010) reports two ultimate limit states in concrete beams due to shear. The first one involves concrete crushing in the direction of compressive principal stress, which is called diagonal compressive collapse. The second one is the crash due to diagonal tension that, in accordance with ABNT NBR 6118 (2014), is resisted by two mechanisms. While a portion of the action force is absorbed by the concrete, the other fraction is resisted by the transverse reinforcements. The diagonal steel belonging to the truss (Figure 5) in these slabs is responsible to shear resistance after concrete curing.

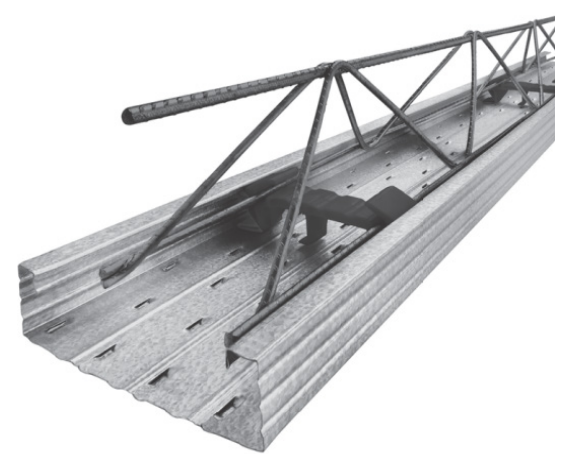

Figure 5: Model of truss coupled to the cold formed profile. 
The resistant shear force in concrete beams, $V_{R d, c}$, should be taken as the smallest of the following values:

$V_{R d, c} \leq\left\{\begin{array}{c}V_{R d 2}=0.54\left(1-\frac{f_{c k}}{250}\right) f_{c d} b_{w 1} d \sin ^{2} \theta(\operatorname{cotg} \alpha+\operatorname{cotg} \theta) \\ V_{R d 3}=0.6 f_{c t d} b_{w 1} d+1.8 \frac{A_{s w}}{s} d(\operatorname{cotg} \alpha+\operatorname{cotg} \theta) \sin \alpha \sin \beta f_{y d}\end{array}\right.$

where $\theta$ is inclination of concrete rods, $\alpha$ is inclination of transversal reinforcements, $\beta$ is inclination of transversal reinforcements in its plane, $d$ is the distance from the center of gravity of tensioned reinforcements set to the top of the section, $f_{c t d}$ is the concrete design resistance to tension, $A_{s w}$ is the total area of transversal reinforcements, $s$ is the distance between successive transversal reinforcements and $f_{y d}$ is yield strength of steel.

\subsubsection{Control of maximum deflection}

The total deflection in a concrete slab may be controlled as well, including the effects of creep and shrinkage. In this sense, ABNT NBR 6118 (2014) restricts its maximum displacement to $L / 350$, where $L$ is the effective span, based on a visual criterion that takes in account the sensory acceptability of users.

This kind of slab, as assumed before, can be analyzed as several juxtaposed T beams. Thus, the calculation of deflection can be done assuming the structural arrangement as simply supported beams. The maximum deflection $\left(f_{e}\right)$ occurs in the mid span, according to Equation 8.

$f_{e}=\frac{5 q_{q p} L^{4}}{384 E_{c s} I_{1}}$

where $q_{q p}$ is the uniformly distributed load for almost permanent load combinations, $L$ is the span, $E_{c s}$ is the concrete secant modulus of elasticity and $l_{1}$ is the second moment of area calculated in the stage $I$, including the contribution of reinforcements.

Then, comparing the bending moment $\left(M_{q p}\right)$ to resistant moment where cracking begins $\left(M_{r}\right)$, adjusts may be done in the moment of inertia to consider the effects of cracking in concrete, which reduces the flexural stiffness. As soon as $M_{q p}$ is increased and overpasses $M_{r}$, more cracked will be the concrete section and less will be the contribution of the cracked portion to bending resistance. Hence, a cubic interpolation is done to consider this effect:

$I_{e}=\left\{\begin{array}{c}I_{1} \quad M_{q p} \leq M_{r} \\ \left(\frac{M_{r}}{M_{q p}}\right)^{3} I_{1}+\left[1-\left(\frac{M_{r}}{M_{q p}}\right)^{3}\right] I_{2} \quad M_{q p}>M_{r}\end{array}\right.$

where $I_{e}$ is the Branson's effective inertia moment and $I_{2}$ is the inertia moment in the stage II (linear distribution of stresses in concrete, discarding tensioned area of the section).

Finally, the total deflection can be calculated using Equation 10:

$f_{t}=f_{e} \frac{I_{1}}{I_{e}}\left(1+\alpha_{f}\right) \leq \frac{L}{350}$

where $\alpha_{f}$ is a coefficient that considers the effects of creep. The maximum deflection may be, at most, equals to $L / 350$. Values greater than this indicate the necessity to reduce the overload first assumed.

\subsubsection{Restrictions to crack width}

The tensile stresses in concrete lead to the appearance of small openings, the cracks, which can be hazardous once they allow the entrance in structure of aggressive agents, causing several damages to concrete and reinforcements. Thus, crack width should be controlled according to the environment where the structure will be built. In the design of these slabs, mostly used for residential buildings, class II was chosen, according to which the maximum crack width $\left(w_{k, \text { max }}\right)$ is $0.3 \mathrm{~mm}$.

The structural check of this serviceability limit state may be done using frequent load combinations to evaluate the stress in the reinforcements in stage II. According to ABNT NBR 6118 (2014), crack width can be calculated as follows: 
$w_{k} \leq\left\{\begin{array}{c}\frac{\phi}{12.5 \eta_{1}} \frac{\sigma_{s}}{E_{s}} \frac{3 \sigma_{s}}{f_{c t m}} \\ \frac{\phi}{12.5 \eta_{1}} \frac{\sigma_{s}}{E_{s}}\left(\frac{4}{\rho_{r}}+45\right)\end{array}\right.$

$w_{k} \leq w_{k, m a ́ x}$

where $\phi$ is the diameter of the biggest steel bar, $\eta_{1}$ is the adhesion coefficient, $E_{s}$ is the steel Young's Module, $f_{c t m}$ is the average concrete tensile strength, $\rho_{r}$ is the passive adherent reinforcement ratio and $\sigma_{s}$ is stress on reinforcements in stage II.

\subsection{Design before concrete curing}

Before the concrete curing, the cold formed steel beam must guarantee structural safety, resisting to bending moment and shear force due to self-weight of concrete, steel beam, light filling material, steel truss and construction overload, taken as $1 \mathrm{kN} / \mathrm{m}^{2}$. Due to high slenderness of cold formed members, plastic analysis is not allowed as in rolled and welded steel. In this sense, the design procedures, according to ABNT NBR 14762 (2010), are based on elastic regime, where all stresses are below the yield strength of the material.

\subsubsection{Ultimate limit state of resistance to combined bending and shear}

The evaluation of the resistant bending moment $\left(M_{R d, s}\right)$ is based on the Direct Strength Method (DSM), where no effective property of cross section is needed. Thus, all the gross geometric properties are directly used as input data and the results are obtained through experimental curves (Figure 6), which consider the geometric imperfections and residual stresses due to cold work. Besides, interaction between local and global buckling is also provided.

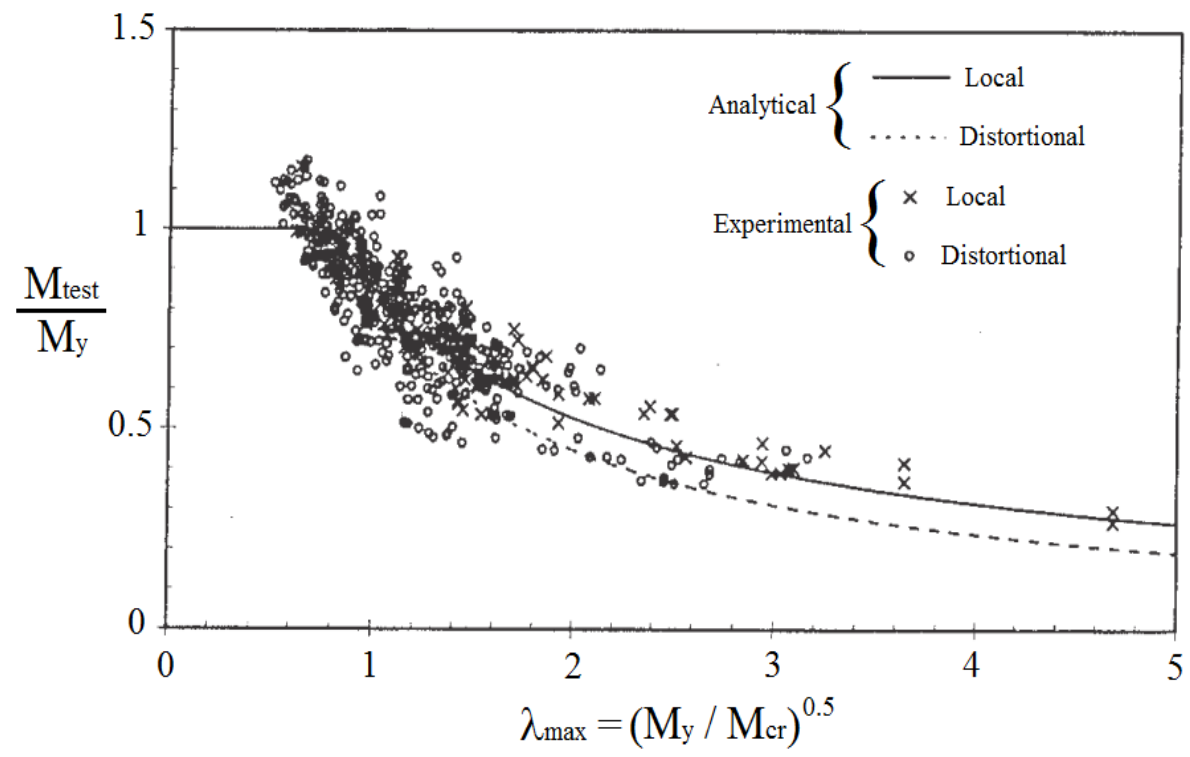

Figure 6: Comparison between theoretical and test data for flexural strength for the DSM (Yu, LaBoube, 2010).

To evaluate the resistant bending moment, global, local and distortional modes of buckling should be considered. The standard procedure consists in determining the reduced slenderness $(\lambda)$ associated to each mode of instability and then, through an experimental curve, estimate the needed parameter.

For global instability:

$\lambda_{0}=\sqrt{\frac{W f_{y}}{M_{e}}}$ 
$M_{R e}=\left\{\begin{array}{c}W f_{y} \quad \lambda_{0} \leq 0.6 \\ 1.11\left(1-0.278 \lambda_{0}^{2}\right) W f_{y} \quad 0.6<\lambda_{0} \leq 1.336 \\ \frac{W f_{y}}{\lambda_{0}^{2}} \quad \lambda_{0}>1.336\end{array}\right.$

where $W$ is the elastic modulus of the section about the minor inertia axis, $f_{y}$ is the steel yield strength, $M_{e}$ is the elastic critical moment of lateral-torsional buckling, obtained from elastic stability analysis and $M_{R e}$ is the characteristic value of resistant bending moment.

For local instability:

$\lambda_{l}=\sqrt{\frac{M_{R e}}{M_{l}}}$

$M_{R l}=\left\{\begin{array}{c}M_{R e} \quad \lambda_{l} \leq 0.776 \\ \frac{M_{R e}}{\lambda_{l}^{0.8}}\left(1-\frac{0.15}{\lambda_{l}^{0.8}}\right) \quad \lambda_{l}>0.776\end{array}\right.$

where $M_{l}$ is the elastic critical moment of local buckling, obtained from elastic stability analysis.

For distortional instability:

$\lambda_{\text {dist }}=\sqrt{\frac{W f_{y}}{M_{\text {dist }}}}$

$M_{\text {Rdist }}=\left\{\begin{array}{c}W f_{y} \quad \lambda_{\text {dist }} \leq 0.673 \\ \frac{W f_{y}}{\lambda_{\text {dist }}}\left(1-\frac{0.22}{\lambda_{\text {dist }}}\right) \quad \lambda_{\text {dist }}>0.673\end{array}\right.$

where $M_{\text {dist }}$ is the elastic critical moment of distortional buckling, obtained from elastic stability analysis.

The final value of resistant moment is the smallest of the three calculated according to Equations 13,15 and 17. Thus:

$M_{R d, s} \leq \frac{1}{1.10}\left\{\begin{array}{c}M_{R e} \\ M_{R l} \\ M_{R d i s t}\end{array}\right.$

Besides, it's necessary to evaluate the maximum shear force resisted by the webs, considering the ultimate limit state of web shear buckling. The following procedure applies to each flat portion of the web, $h$, thus every flat part may be accounted for the final shear resistance. In addition, no stiffener is provided, so $k_{v}$, the coefficient of web shear buckling, may be taken as 5 .

$\lambda_{w}=\frac{h}{t}$

$A=1.08 \sqrt{\frac{E_{s} k_{v}}{f_{y}}} B=1.40 \sqrt{\frac{E_{s} k_{v}}{f_{y}}}$

$V_{R d, s} \leq\left\{\begin{array}{cl}\frac{0.6 h t f_{y}}{1.10} & \lambda_{w} \leq A \\ \frac{0.65 t^{2} \sqrt{k_{v} f_{y} E_{s}}}{1.10} & A<\lambda_{w} \leq B \\ \frac{0.905 E_{s} k_{v} t^{3}}{1.10 h} & \lambda_{w}>B\end{array}\right.$

where $h$ is the flat portion of the web, $t$ is the web thickness, $E_{s}$ is the steel Young's Modulus and $f_{y}$ is the steel yield strength. 
Finally, once $M_{R d, s}$ and $V_{R d, s}$ are determined for a given reference span, $L$, to assure the structural safety, the following relationship has to be verified.

$$
\left(\frac{M_{s d, s}}{M_{R d, s}}\right)^{2}+\left(\frac{V_{s d, s}}{V_{R d, s}}\right)^{2} \leq 1
$$

\subsubsection{Control of maximum deflection}

In this phase, before concrete curing, the cold formed beam acts as a steel formwork, which may be stiff enough to assure the geometry and dimensions of designed structures and be tight to avoid grout flow, according to ABNT NBR 15696 (2009). The same standard indicates the limit of $1+\mathrm{L} / 500, \mathrm{~mm}$, for the maximum deflection of formwork, where $L$ is the span. Although, once it will not be removed, the criterion for composite slabs from ABNT NBR 8800 (2008), less severe, is used.

In the elastic regime, considering the structural system a simply supported beam, the maximum deflection is obtained as:

$f_{S}=\frac{5 q_{s e r v} L^{4}}{384 E_{S} I_{e f}} \leq\left\{\begin{array}{l}\frac{L}{180} \\ 2 \mathrm{~cm}\end{array}\right.$

where $q_{\text {serv }}$ is the distributed load for construction serviceability load combinations, $L$ is the span, $E_{s}$ is the steel Young's Modulus and $I_{e f}$ is the effective second moment of area of the cold formed profile, obtained through the Direct Strength Method.

On the other hand, if the deflection, below the settled limit, exceeds the value of $L / 250$, an extra layer of concrete will be deposited above the slab and the extra self-weight may be used to calculate a new deflection. The load $q_{\text {serv }}$ is increased by the weight of a layer of concrete whose thickness is $70 \%$ of the displacement previously evaluated. Thereby, the new deflection may respect the limits shown in Equation 23.

\subsection{Calculation steps}

In the sequence, the design steps of trussed slabs with steel formwork in cold formed $U$ profile are presented through a flow chart (Figure 7).

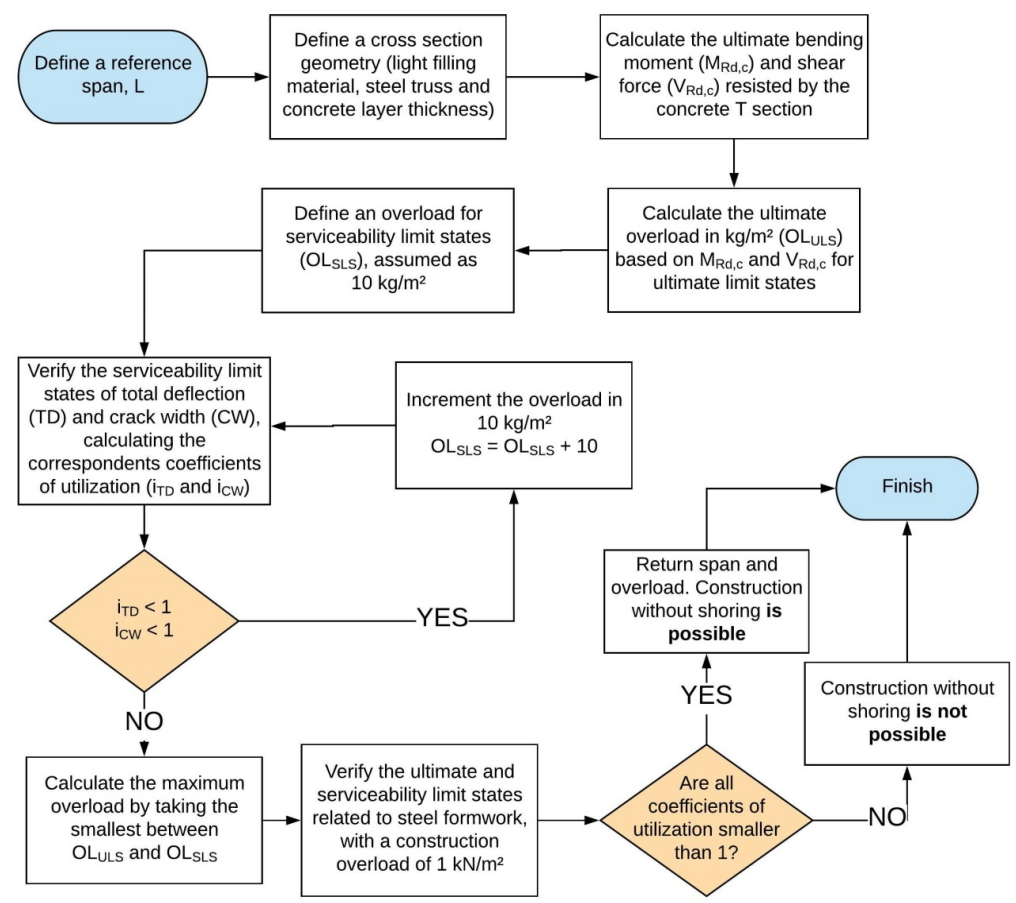

Figure 7: Design flow chart. 


\section{NUMERICAL BUCKLING ANALYSIS}

The design of cold formed steel members using the DSM involves the determination of critical moments of lateraltorsional, local and distortional buckling through elastic stability analysis. In this sense, numerical analyses were carried using Ansys ${ }^{\circledR} 14.0$ (ANSYS, 2011) to simulate a cold formed simply supported beam, whose cross section is indicated in Figure 2, for different spans, from 0.6 to $2.0 \mathrm{~m}$ with steps of $0.2 \mathrm{~m}$.

The element used was the 4-Node Shell 181 (Figure 8), suitable for analyzing thin to moderately-thick shell structures, with six degrees of freedom at each node (translations in the $x, y$ and $z$ directions and rotations about the same axes). It's well-suited for both linear and non-linear analysis, using full and reduced integration schemes in the element domain. Besides, its formulation is based on logarithmic strain and true stress measures.

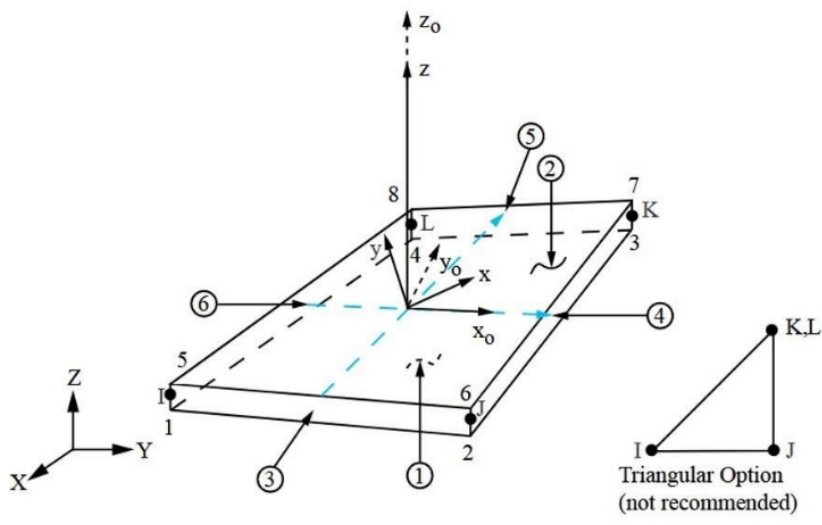

(a) 4-Node Shell 181 finite element (ANSYS, 2011).

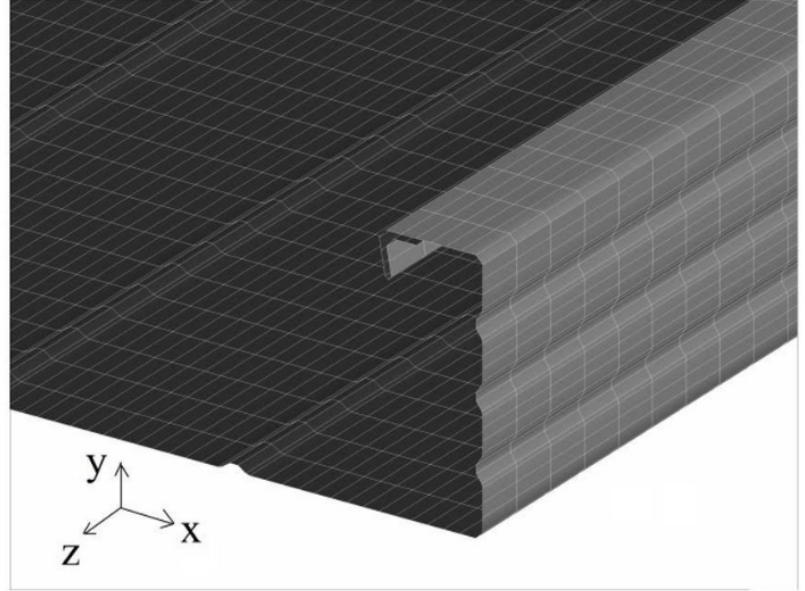

(b) Finite element model, with mesh evidenced.

Figure 8: Numerical model information.

At the boundary, the fork support is a needed condition to evaluate the buckling critical bending moments. At each support, translations were fixed in the $x$ direction in the webs' plane portions and in the $y$ direction in the bottom flange's plane portion, which means that intermediate stiffeners are free. Besides, along the $z$ axis, the longitudinal axis of the beam, a single node at the geometric center of the web was fixed in order to prevent displacements in this direction due to horizontal forces on account of bending moment. This scheme is illustrated in Figure 9.

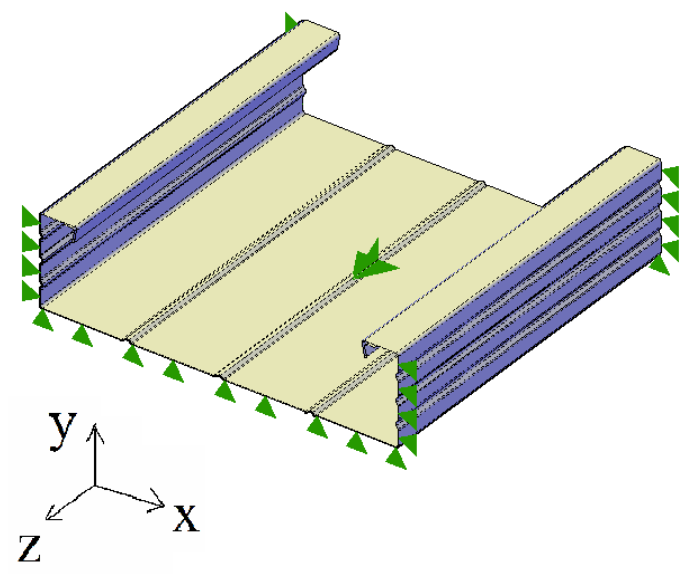

Figure 9: Fork support - boundary conditions.

Furthermore, the buckling analysis was performed using Lanczos Method for eigenvalue extraction. For each span, 80 buckling modes were extracted in order to find the required instability modes. This kind of numerical procedure expects a previous static analysis in order to assign to the finite element model forces that will cause the investigated buckling modes. In this case of elastic flexure, nodal forces were applied in all z-axis edge nodes, assuming an elastic 
distribution of stresses due to a unitary bending moment (1 Nm). Thus, the whole beam is uniformly bent about the less stiff principal axis (Figure 10).

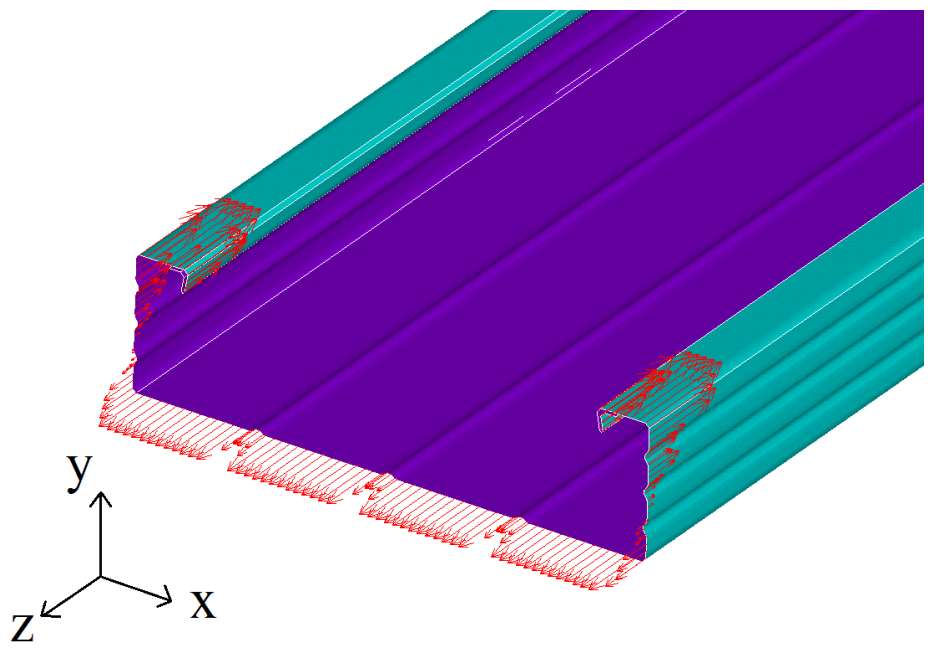

Figure 10: Edge forces due to the action of bending moment.

Finally, before performing the buckling analysis, the mesh size was determined. For a predefined span, $2 \mathrm{~m}, 40$ mesh sizes were tested and the first critical buckling load has been evaluated. A 2 mm mesh was chosen due to reduced dimension of cold formed profile and its tiny stiffeners.

\section{ANALYSIS RESULTS}

\subsection{Numerical experiments}

In this section, the results of numerical analysis will be presented. For each span, three critical bending moments were determined: lateral-torsional, local and distortional. Table 1 shows the outputs, where all the moments were calculated in $\mathrm{Nm}$.

Table 1: Critical bending moments of buckling of cold formed steel $U$ profile.

\begin{tabular}{cccccccccc}
\hline \multirow{2}{*}{$\mathbf{L}(\mathbf{m})$} & \multicolumn{3}{c}{$\mathbf{0 . 6 5} \mathbf{~ m m}$} & \multicolumn{3}{c}{$\mathbf{0 . 8 0} \mathbf{~ m m}$} & \multicolumn{3}{c}{$\mathbf{1 . 0 8} \mathbf{~ m m}$} \\
\cline { 2 - 9 } & $\mathbf{M}_{\mathbf{e}}$ & $\mathbf{M}_{\mathbf{L}}$ & $\mathbf{M}_{\text {dist }}$ & $\mathbf{M}_{\mathrm{e}}$ & $\mathbf{M}_{\mathbf{L}}$ & $\mathbf{M}_{\text {dist }}$ & $\mathbf{M}_{\mathrm{e}}$ & $\mathbf{M}_{\mathrm{L}}$ & $\mathbf{M}_{\text {dist }}$ \\
\hline 0.6 & 1151.67 & 1147.35 & 575.71 & 1498.2 & 1779.33 & 909.85 & 2034.28 & 3339.66 & 1791.97 \\
0.8 & 1083.7 & 1147.67 & 645.93 & 1407.8 & 1755.00 & 967.32 & 1919.02 & 3295.76 & 1653.20 \\
1.0 & 911.2 & 1180.82 & 598.68 & 1204.6 & 1742.02 & 899.84 & 1632.61 & 3280.70 & 1664.75 \\
1.2 & 613.37 & 1154.94 & 588.39 & 870.56 & 1734.47 & 931.62 & 1287.49 & 3274.93 & 1661.51 \\
1.4 & 537.23 & 1145.20 & 618.19 & 721.36 & 1730.16 & 912.76 & 1007.27 & 3270.47 & 1645.39 \\
1.6 & 451.23 & 1146.95 & 591.77 & 588.07 & 1727.42 & 905.88 & 802.11 & 3266.34 & 1667.83 \\
1.8 & 375.35 & 1115.07 & 590.49 & 482.83 & 1725.79 & 926.09 & 652.92 & 3264.42 & 1647.33 \\
2.0 & 314.12 & 1113.94 & 604.53 & 401.90 & 1724.53 & 908.74 & 542.65 & 3263.31 & 1680.74 \\
\hline
\end{tabular}

where $M_{e}$ is the lateral-torsional critical moment (LTCM), $M_{L}$ is the local critical moment (LCM) and $M_{\text {dist }}$ is the distortional critical moment (DCM), for the three different analyzed thicknesses.

It's important to state that when the thickness was first increased from 0.65 to $0.80 \mathrm{~mm}$, a $31 \%$ average increased has been observed in the LTCM and 53\% for both LCM and DCM. Then, when the thickness was changed to $1.08 \mathrm{~mm}$, LTCM, LCM and DCM were increased in $80 \%, 189 \%$ and $180 \%$, respectively, based on the elementary case (0.65 mm). Moreover, the gain in the critical moments may represent a growth in the resistance of the beam, i.e., the current bending moment that causes collapse is greater than the original one. Table 1 is graphically represented in Figures 11 , 12 and 13 


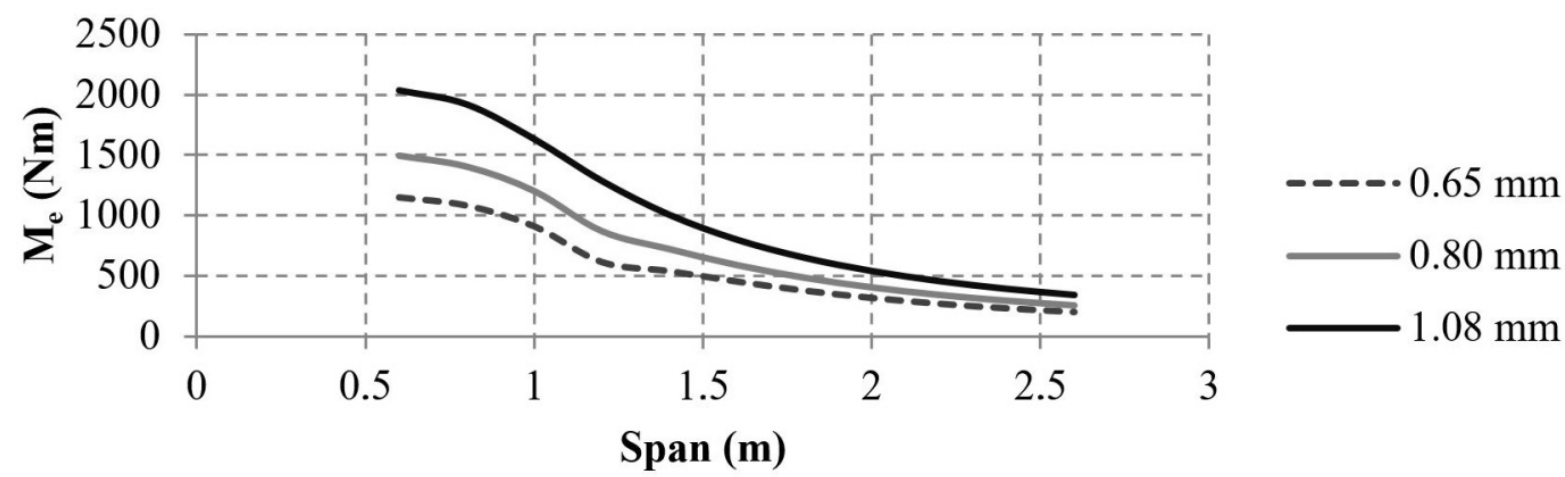

Figure 11: $M_{e} x$ span for different thicknesses.

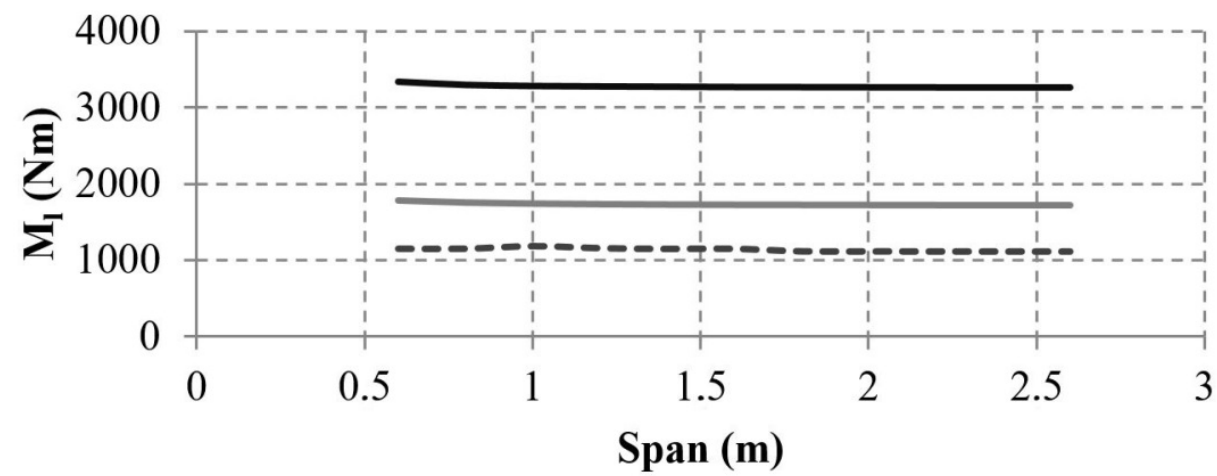

$---\cdot 0.65 \mathrm{~mm}$

$0.80 \mathrm{~mm}$

$-1.08 \mathrm{~mm}$

Figure 12: $M_{L}$ x span for different thicknesses.

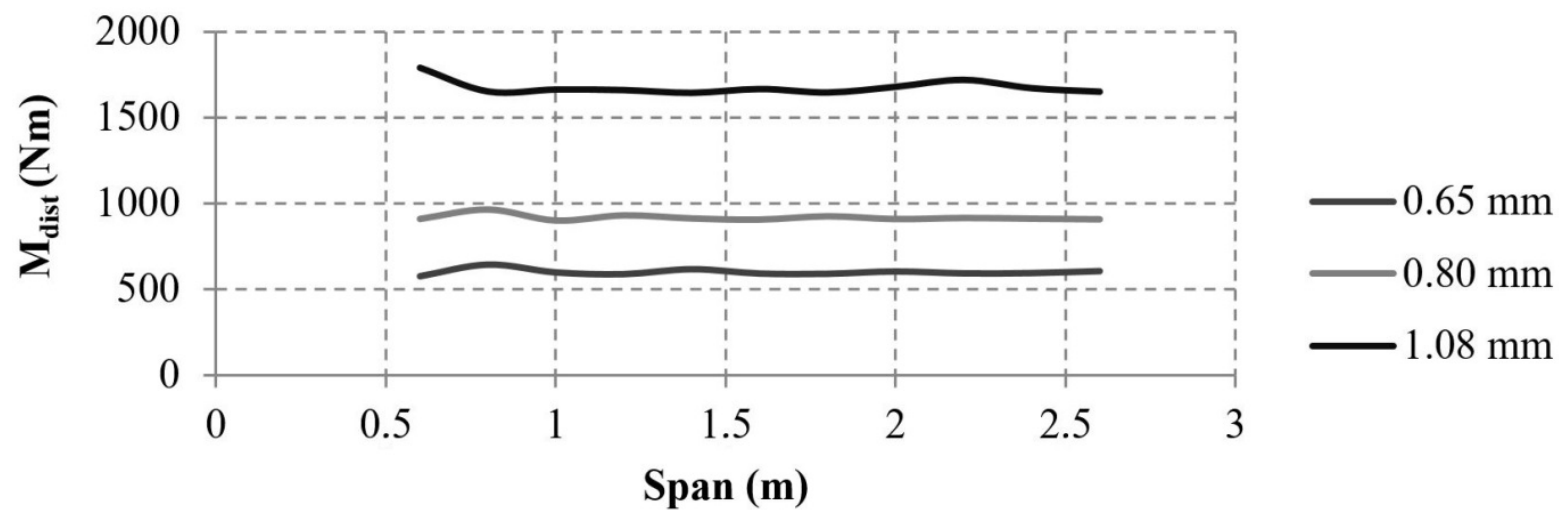

Figure 13: $M_{\text {dist }} x$ span for different thicknesses.

\subsection{Spans and overloads without shoring}

The evaluation of the resistance of trussed slabs with steel formwork in cold formed $U$ profile is mainly associated to the input predefined cross section geometry and material's mechanical properties. Besides, the model of truss incorporated to the ribs also affects the relationship between span and overload, expressed in $\mathrm{kg} / \mathrm{m}^{2}$. Thus, a design table can be arranged by making different combinations of entering data.

In order to exemplify the results of the proposed design procedure, two geometries were selected and the analysis results were presented here. The same type of concrete was used, with compressive strength of $25 \mathrm{MPa}$, and also the truss, model 8645, whose yield strength is $600 \mathrm{MPa}$. Besides, the light filling material was chosen in accordance with ABNT NBR 14859-2 (2016), which specific weight was taken as $0.37 \mathrm{kN} / \mathrm{m}^{3}$.

a) Scenario 1: concrete layer thickness of $5 \mathrm{~cm}$, light filling blocks $27 \times 8 \mathrm{~cm}$ and 2 steel bars of $\varnothing 6.3 \mathrm{~mm}$ as additional reinforcement, $f_{y k}=500 \mathrm{MPa}$;

b) Scenario 2: concrete layer thickness of $6 \mathrm{~cm}$, light filling blocks $37 \times 8 \mathrm{~cm}$ and 2 steel bars of $\varnothing 6.3 \mathrm{~mm}$ as additional reinforcement, $f_{y k}=500 \mathrm{MPa}$; 
For each scenario, the three different cold formed plated thicknesses were tested to verify how this parameter influences in the maximum span without shoring. Finally, the cold formed steel has yield strength of $340 \mathrm{MPa}$, for all cases.

For the next results, the following convention must be used to indicate the limit states related to design procedure: $\mathrm{BM} A C$ - bending moment after curing; SF AC - shear force after curing; DEF AC - maximum deflection after curing; CW AF - crack width after curing; BS BC - combined bending and shear before curing; and DEF BC - maximum deflection before curing.

\subsubsection{Scenario 1}

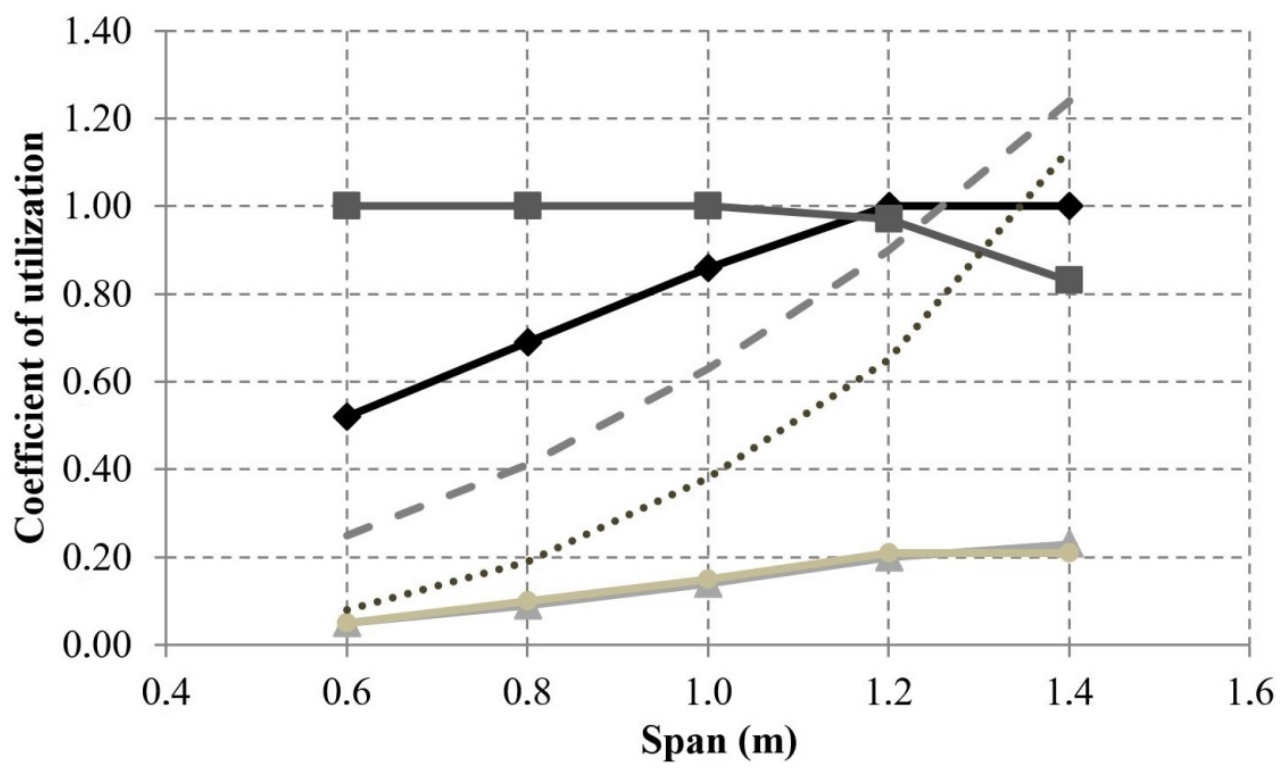

Figure 14: Analysis results for scenario 1 - steel thickness of $0.65 \mathrm{~mm}$.
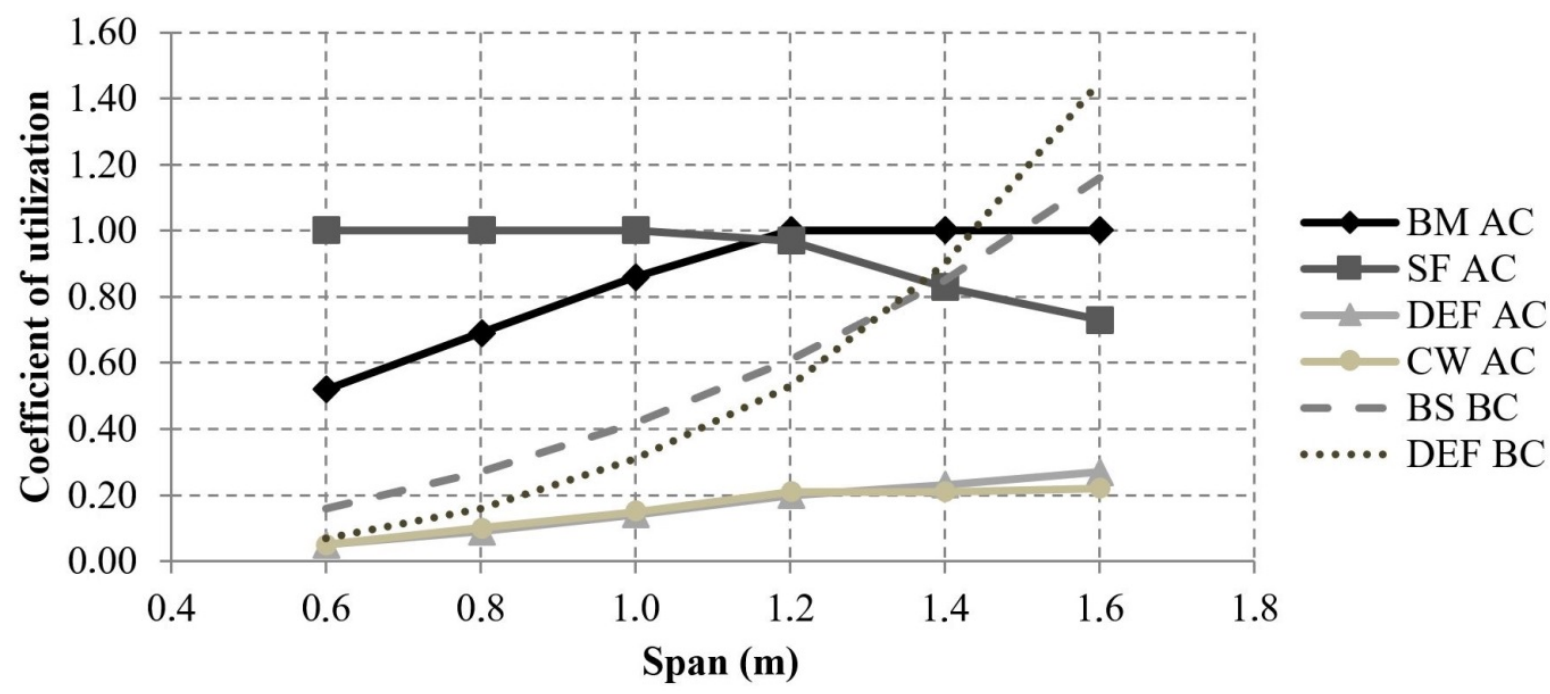

Figure 15: Analysis results for scenario 1 - steel thickness of $0.80 \mathrm{~mm}$. 


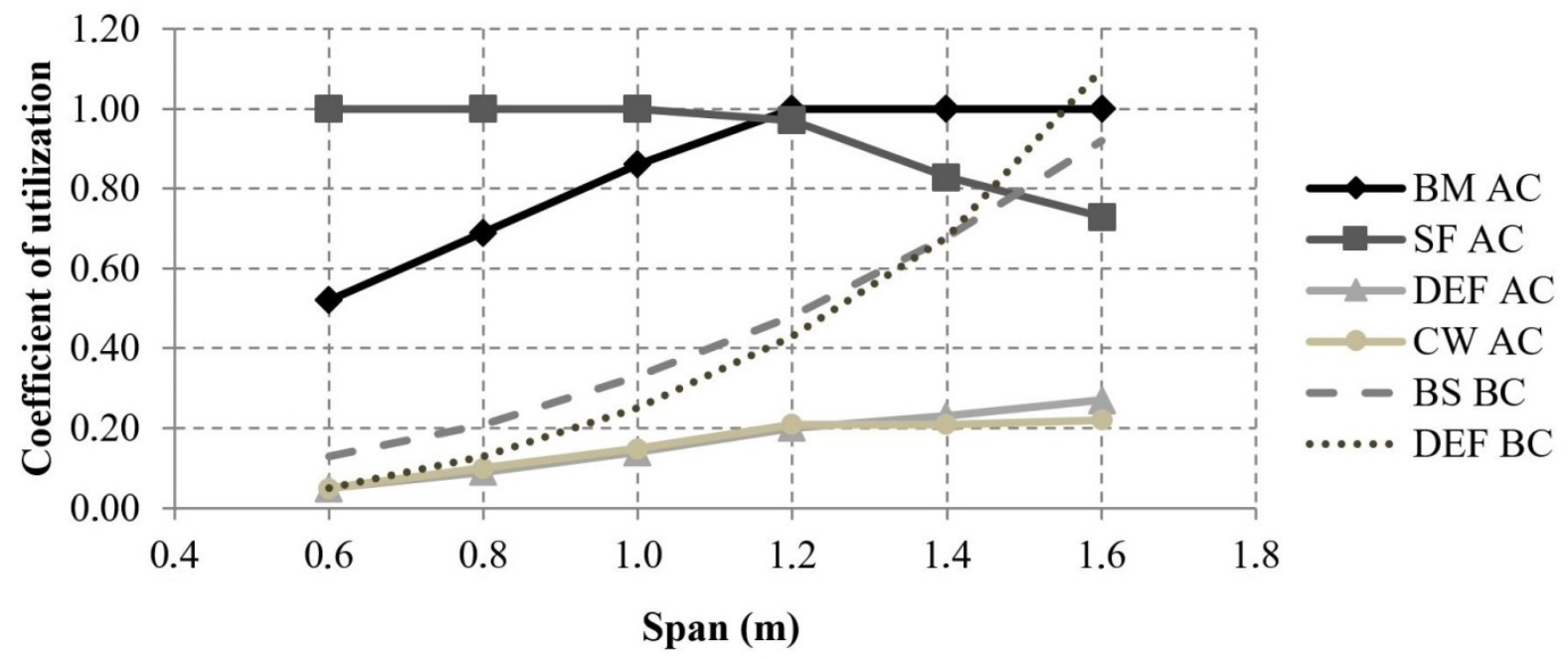

Figure 16: Analysis results for scenario 1 - steel thickness of $1.08 \mathrm{~mm}$.

In accordance with Figures 14 to 16 , the design is governed by the ultimate limit states for short spans. The ultimate limit of resistance to shear force restricts the overload when the span is below $1.0 \mathrm{~m}$, which was already expected for short slabs, and bending moment does in the other cases. Moreover, the serviceability limit states no longer influence in the ultimate load for the presented cases, but would do for larger spans, over $3.2 \mathrm{~m}$, which is limited by total deformation of concrete (DEF AC).

In addition, the maximum span without shoring also varies according to steel plate thickness. For $0.65 \mathrm{~mm}$-thick plates, simply supported slabs with $1.2 \mathrm{~m}$ can be safely built. For the other cases, $0.80 \mathrm{~mm}$-thick plates and $1.08 \mathrm{~mm}$ thick plates, respectively, the span is increased in $20 \mathrm{~cm}$, reaching $1.4 \mathrm{~m}$. It's important to observe that, whereas the steel plate had its thickness increased in $35 \%$ and the coefficient of utilization related to interaction between bending and shear got smaller than 1, the total deformation was the one that restricted the gains, according to Figure 16 (coefficient of utilization of 1.10). That could be solved by changing the deformation limits in Equation 23, which was suggested by ABNT NBR 8800 (2008).

\subsubsection{Scenario 2}

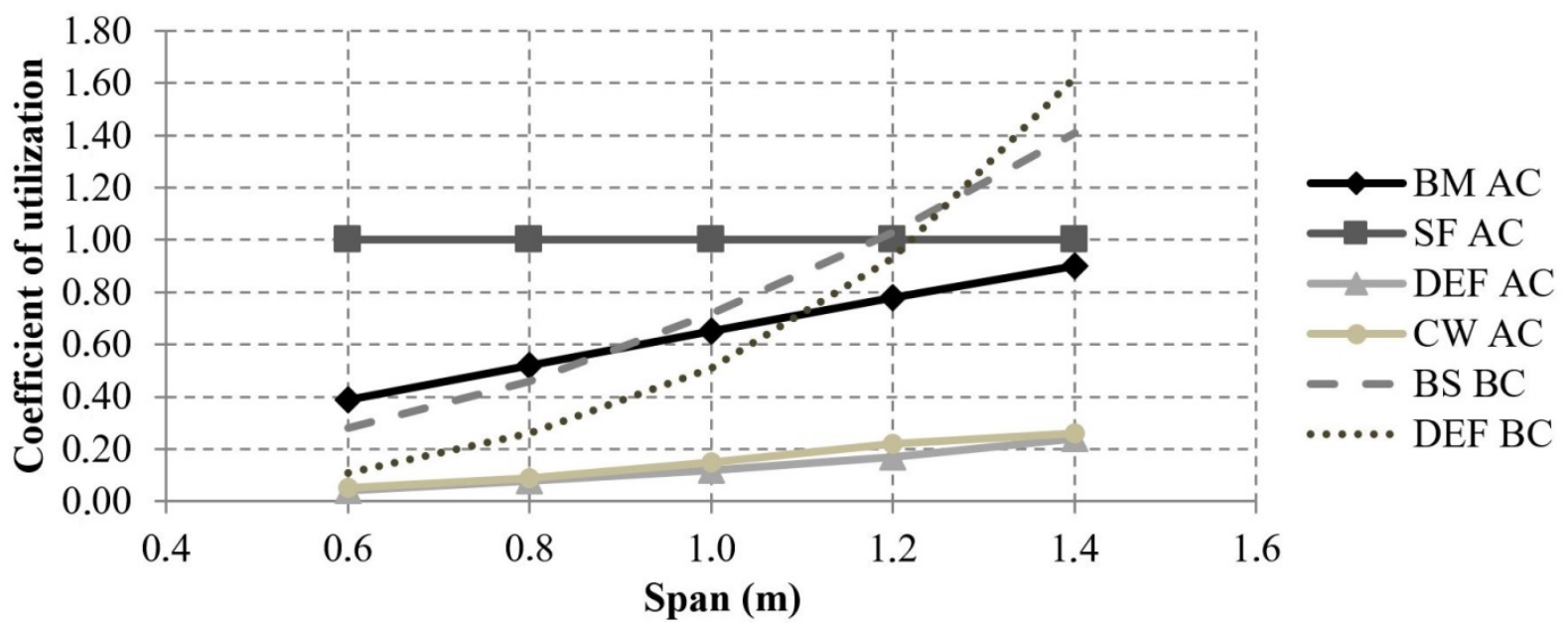

Figure 17: Analysis results for scenario 2 - steel thickness of $0.65 \mathrm{~mm}$ 


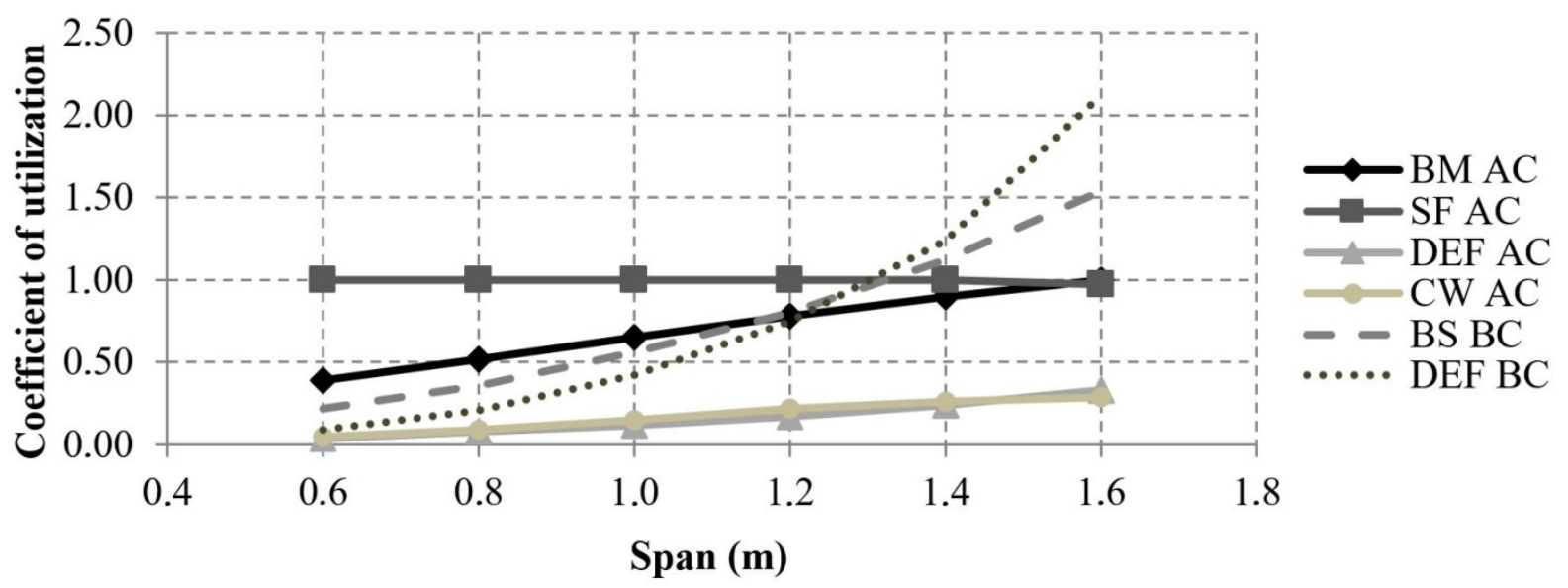

Figure 18: Analysis results for scenario 2 - steel thickness of $0.80 \mathrm{~mm}$.

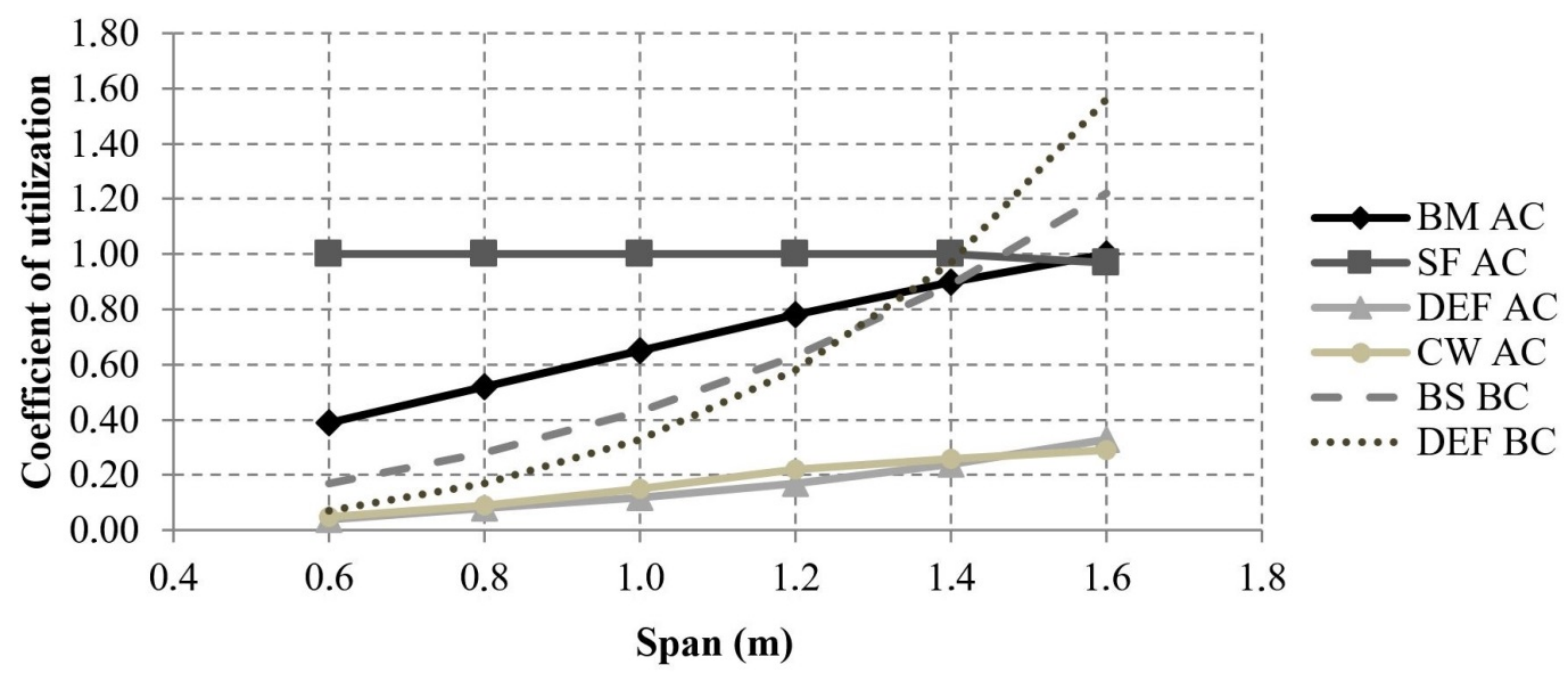

Figure 19: Analysis results for scenario 2 - steel thickness of $1.08 \mathrm{~mm}$.

In accordance with Figures 17 to 19, the design is governed by the ultimate limit states for short spans, the same observed in the previous case. The ultimate limit of resistance to shear force restricts the overload when the span is below $1.4 \mathrm{~m}$ and bending moment does in the other cases. Moreover, the serviceability limit states no longer influence in the ultimate load for the presented cases, but would do for larger spans, over $3.0 \mathrm{~m}$, which is limited by total deformation of concrete (DEF AC).

In addition, the maximum span without shoring also varies according to steel plate thickness. For $0.65 \mathrm{~mm}$-thick plates, simply supported slabs with $1.0 \mathrm{~m}$ can be safely built. For the other cases, $0.80 \mathrm{~mm}$-thick plates and $1.08 \mathrm{~mm}$ thick plates, respectively, the span is increased in $20 \mathrm{~cm}$ and $40 \mathrm{~cm}$, reaching $1.2 \mathrm{~m}$ and $1.4 \mathrm{~m}$.

Comparing scenarios 1 and 2, the maximum overload can be plotted against span. It's possible to observe an inversely proportional relation between them (Figure 20). Short spans can resist to the action of a huge overload, characterized by the collapse due to shear force. Once the distance between steel formworks in scenario 2 is greater than that for scenario 1, it was expected that the overload would be smaller, up to spans of $1.2 \mathrm{~m}$. On the other hand, from this moment on, the ultimate resistance is governed by bending moment, thus the wider flange of $T$ section of case 2 contributes to increase the resistance when compared to scenario $1 \mathrm{~T}$ section, preserving the same additional reinforcements and the same steel truss, for both cases. 


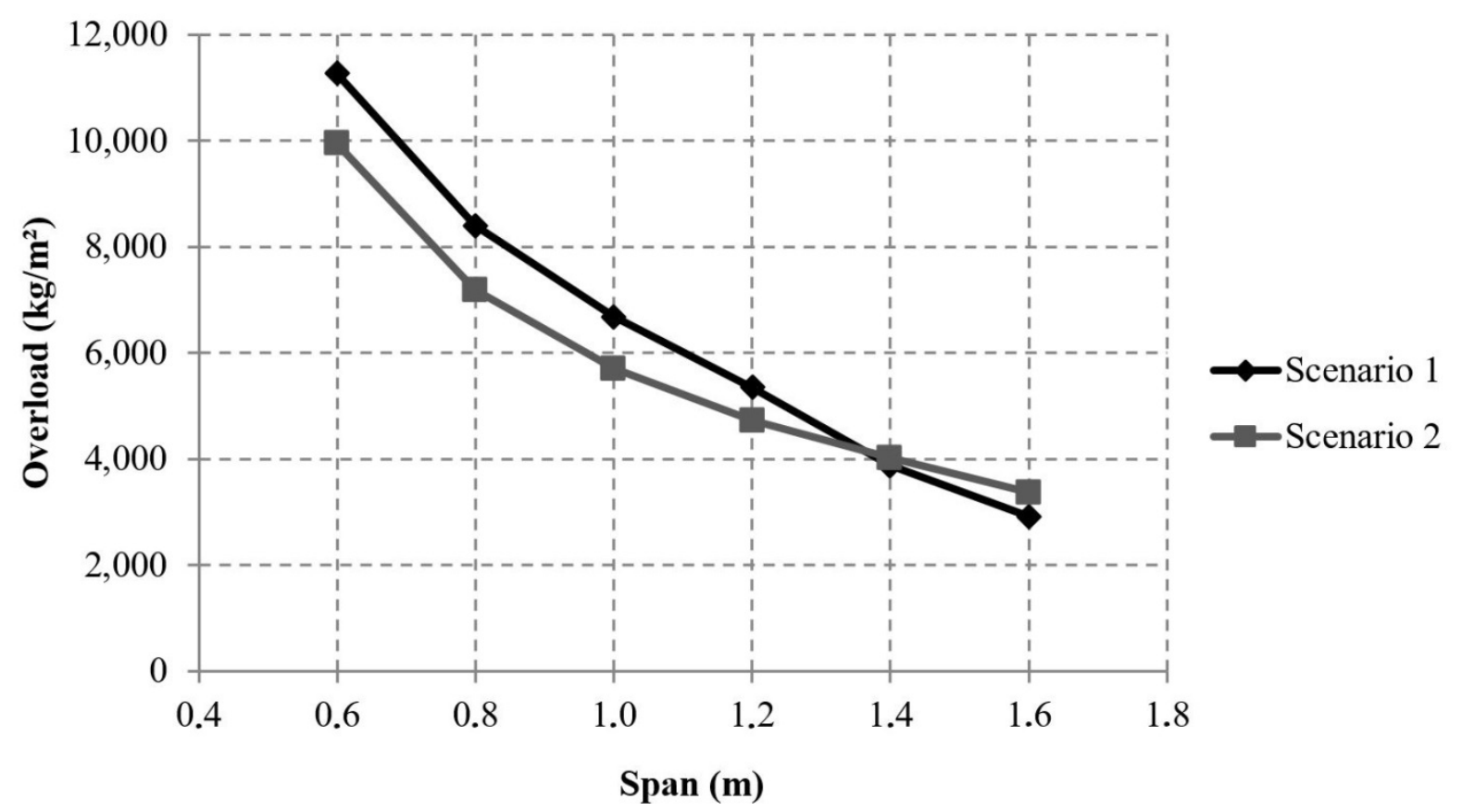

Figure 20: Overloads for scenarios 1 and 2.

\section{CONCLUSIONS}

In this paper, a new design procedure for hybrid steel-concrete trussed slabs was proposed, whilst no data about the mechanical composed behavior is provided from full scale tests. Thus, no interaction was considered, in the sense that concrete resist to all loads its lifetime, after curing, and steel formwork does before concrete curing. National Brazilian Codes ABNT NBR 14762 (2010), ABNT NBR 6118 (2014), ABNT NBR 8800 (2008) and ABNT NBR 14859-2 (2016) supplied technical information in which the whole methodology was based.

First of all, all cases may be analyzed as single ones, i.e., each combination of concrete compressive strength $\left(f_{c k}\right)$, light filling material (specific weight and dimensions), steel truss model and additional reinforcements (size, quantity and yield strength) leads to a curve overload versus span, an useful tool for structural engineers when dealing with design of this kind of slab. In general, the overload is controlled by a different limit state depending on the situation: for short spans, up to $1.2 \mathrm{~m}$, shear force is the limiting factor; for medium spans, from 1.4 to $3.0 \mathrm{~m}$, bending moment is the limiting one; and for long spans, total deflection is the limiting factor, on average.

In addition, the cold formed steel formwork, which guarantees structural safety on construction stage, conditions the maximum span length without shoring. It may be observed that the employed profile was first intended to be fabricated with $0.65 \mathrm{~mm}$ of plate thickness, which implies, associated to the reduced dimension of $U$ section $(120 \times 31 \mathrm{~mm})$, a low moment of inertia and a low elastic modulus of resistance about the bending axis. In this sense, no large spans were expected before the analysis was actually carried, reason why a parametric study of thickness was proposed to evaluate its influence in the maximum span without shoring.

Finally, two similar arrangements have been chosen to demonstrate that different spans can be reached without shoring depending on the data entry and on the steel formwork geometry as well. The results have shown that a span without shoring of $1.2 \mathrm{~m}$ can be built when a plate thickness of $0.65 \mathrm{~mm}$ is used. On the other hand, when the plate thickness is $0.80 \mathrm{~mm}$ or $1.08 \mathrm{~mm}$, the span without shoring can reach $1.4 \mathrm{~m}$, for the first case. Then, putting the formworks $10 \mathrm{~cm}$ away from its original position in case 1 by using a light filling block $10 \mathrm{~cm}$ wider $(37 \times 8 \mathrm{~cm})$ and also increasing in $1 \mathrm{~cm}$ the concrete layer thickness, the maximum spans were reduced to $1.0 \mathrm{~m}, 1.2 \mathrm{~m}$ and $1.4 \mathrm{~m}$, respectively.

The output results show that short spans can be used without shoring so far, up to $1.2 \mathrm{~m}$ for the original steel formwork geometry. Although, this theoretical value will probably be increased after considering the mechanical coupled behavior between formwork and steel truss in bending. In the worst case, no longitudinal interaction is provided and only the vertical displacement in the mid span is coupled. Then, two neutral axes are present in the resistant section (one in the profile and the other in the truss), each one resisting to a portion of applied bending 
moment. Thus, a longer span without shoring is expected. On the other hand, numerical experiments will be performed followed by full scale tests to confirm this assumption and verify the accuracy of the proposed formulation.

\section{ACKNOWLEDGMENTS}

The authors acknowledge ArcelorMittal and Federal University of Espirito Santo for the financial support during the development of this research.

Author's Contributions: Conceptualization, LF Favarato; Methods, LF Favarato, AFG Calenzani, JC Vianna Pires, E Junges and JA Ferrareto; Writing - original draft, LF Favarato; Writing - review and editing, LF Favarato, AFG Calenzani, JC Vianna Pires, E Junges and JA Ferrareto; Resources, JA Ferrareto; Supervision, AFG Calenzani and JA Ferrareto.

Editor: Adnan Ibrahimbegovic. Paulo de Mattos Pimenta.

\section{References}

ANSYS: Engineering Analysis System. Version 14.0, 2011.

Araújo, J. M. (2010). Curso de Concreto Armado, (3a edição), Editora Dunas, Rio Grande, RS, Brazil.

ASSOCIAÇÃO BRASILEIRA DE NORMAS TÉCNICAS (2008). NBR 8800, Projeto de estruturas de aço e de estruturas mistas de aço e concreto de edifícios, Rio de Janeiro.

ASSOCIAÇÃO BRASILEIRA DE NORMAS TÉCNICAS (2009). NBR 15696, Fôrmas e escoramentos para estruturas de concreto Projeto, dimensionamento e procedimentos executivos, Rio de Janeiro.

ASSOCIAÇÃO BRASILEIRA DE NORMAS TÉCNICAS (2010). NBR 14762, Dimensionamento de estruturas de aço constituídas por perfis formados a frio, Rio de Janeiro.

ASSOCIAÇÃO BRASILEIRA DE NORMAS TÉCNICAS (2014). NBR 6118, Projeto de estruturas de concreto - procedimento, Rio de Janeiro.

ASSOCIAÇÃO BRASILEIRA DE NORMAS TÉCNICAS (2016). NBR 14859-2, Lajes pré-fabricadas de concreto - Parte 2 - Elementos inertes para enchimento e fôrma - Requisitos, Rio de Janeiro.

Carvalho, P. R. M.; Grigoletti, G.; \& Barbosa, G. D. (2014). Curso Básico de Perfis de Aço Formados a Frio, (3 ${ }^{\text {rd }}$ edition), Porto Alegre, RS, Brazil.

Cheng, S. S.; Kim, B.; \& Li, L. Y. (2013). "Lateral-torsional buckling of cold-formed channel sections subject to combined compression and bending". Journal of Constructional Steel Research, 80, 174-180.

Glauz, R. S. (2017). "Elastic lateral-torsional buckling of general cold-formed steel beams under uniform moment". Thin-Walled Structures, 119, 586-592.

Grossi, L. G. F. (2016). "On the structural behavior and the design of composite slabs with additional reinforcement" (in Portuguese), M. Sc. Dissertation, University of São Paulo, São Carlos.

Ibrahimbegovic, A., Hajdo, E., \& Dolarevic, S. (2013), "Linear instability or buckling problems for mechanical and coupled thermomechanical extreme conditions". Coupled systems mechanics, 2(4), 349-374.

Javaroni, C. E. (2015). Estruturas de Aço: Dimensionamento de Perfis Formados a Frio, (1 $1^{\text {st }}$ edition), Elsevier, Rio de Janeiro, RJ, Brazil.

Kankanamge, N. D.; \& Mahendran, M. (2012). "Behaviour and design of cold-formed steel beams subject to lateral-torsional buckling". Thin-walled structures, 51, 25-38.

Ngo, V. M.; Ibrahimbegovic, A.; \& Hajdo, E. (2014). "Nonlinear instability problems including localized plastic failure and large deformations for extreme thermo-mechanical loads". Coupled systems mechanics, 3(1), 89-110.

Sieg, A. P. A. (2015). "Study of a Slab System with Incorporated Sheeting" (in Portuguese), M. Sc. Dissertation, University of São Paulo, São Carlos. 
Silva, E. L.; Pierin, I.; \& Silva, V. P. S. (2014). Estruturas Compostas por Perfis Formados a Frio: Dimensionamento pelo Método das Larguras Efetivas e Aplicação conforme ABNT NBR 14762:2010 e ABNT NBR 6355:2012,Instituto do Aço Brasil, Rio de Janeiro, RJ, Brazil.

Takey, T. H. (2001). “Composite slab system for buildings using cold formed steel profiles” (in Portuguese), M. Sc. Dissertation, Pontifícia Universidade Católica do Rio de Janeiro, Rio de Janeiro.

Vianna, J. C. (2005). "Composite slab system for residential constructions using cold formed steel plates with embossments" (in Portuguese), M. Sc. Dissertation, Pontifícia Universidade Católica do Rio de Janeiro, Rio de Janeiro.

Yu, W.W.; LaBoube, R. A. (2010). Cold-Formed Steel Design, (4th edition), John Wiley \& Sons, Inc., Hoboken, New Jersey, USA. 